\title{
BMJ Open Study protocol for the assessment of nurses internal contamination by antineoplastic drugs in hospital centres: a cross-sectional multicentre descriptive study
}

\author{
Antoine Villa, ${ }^{1,2,3}$ Mathieu Molimard, ${ }^{1,3,4}$ Emmanuelle Bignon, ${ }^{5}$ Béatrice Martinez, ${ }^{1,3}$ \\ Magali Rouyer, ${ }^{5}$ Simone Mathoulin-Pelissier, ${ }^{1,3}$ Isabelle Baldi, ${ }^{1,3,6}$ \\ Catherine Verdun-Esquer, ${ }^{6}$ Mireille Canal-Raffin (1) ${ }^{1,3,4}$
}

To cite: Villa A, Molimard M, Bignon $\mathrm{E}$, et al. Study protocol for the assessment of nurses internal contamination by antineoplastic drugs in hospital centres: a crosssectional multicentre descriptive study. BMJ Open 2019;9:e033040. doi:10.1136/ bmjopen-2019-033040

- Prepublication history for this paper is available online. To view these files, please visit the journal online (http://dx.doi. org/10.1136/bmjopen-2019033040).

Received 17 July 2019 Revised 18 September 2019 Accepted 07 October 2019

D Check for updates

(C) Author(s) (or their employer(s)) 2019. Re-use permitted under CC BY-NC. No commercial re-use. See rights and permissions. Published by BMJ.

For numbered affiliations see end of article.

Correspondence to Dr Mireille Canal-Raffin; mireille.canal-raffin@ubordeaux.fr

\section{ABSTRACT}

Introduction Antineoplastic drugs (AD) are potentially carcinogenic and/or reprotoxic molecules. Healthcare professionals are increasingly exposed to these drugs and can be potentially contaminated by them. Internal contamination of professionals is a key concern for occupational physicians in the assessment and management of occupational risks in healthcare settings. Objectives of this study are to report AD internal contamination rate in nursing staff and to identify factors associated with internal contamination.

Methods and analysis This trial will be conducted in two French hospital centres: University Hospital of Bordeaux and IUCT-Oncopole of Toulouse. The target population is nurses practicing in one of the fifteen selected care departments where at least one of the five studied $A D$ is handled (5-fluorouracil, cyclophosphamide, doxorubicin, ifosfamide, methotrexate). The trial will be conducted with the following steps: (1) development of analytical methods to quantify $A D$ urine biomarkers, (2) study of the workplace and organization around $A D$ in each care department (transport and handling, professional practices, personal and collective protection equipments available) (3) development of a self-questionnaire detailing professional activities during the day of inclusion, (4) nurses inclusion (urine samples and self-questionnaire collection), (5) urine assays, (6) data analysis.

Ethics and dissemination The study protocol has been approved by the French Advisory Committee on the Treatment of Information in Health Research (CCTIRS) and by the French Data Protection Authority (CNIL). Following the opinion of the Regional Committee for the Protection of Persons, this study is outside the scope of the provisions governing biomedical research and routine care $\left(n^{\circ} 2014 / 87\right)$. The results will be submitted to peerreviewed journals and reported at suitable national and international meetings.

Trial registration number NCT03137641.

\section{INTRODUCTION}

The number of cancer cases is constantly increasing worldwide and consequently, the
Strengths and limitations of this study

- For reliable detection and to reduce the number of misclassifications as uncontaminated, the analytical methods used will to be specific, highly sensitive, will use isotopic internal standard to normalise urine matrix effect and the antineoplastic drugs (AD) urine stability during storage will be studied.

- Exposure biomarkers of five ADs will be analysed in each urine sample and $A D$ concentration will be expressed in $\mathrm{ng} / \mathrm{L}$ and in $\mathrm{ng} / \mathrm{g}$ of urinary creatinine to account for urine dilution.

- The care departments of the study are selected among different medical specialties.

- The data from the self-questionnaires coupled with the results of the urine assays will serve to identify factors associated with internal contamination.

- This study will only assess the internal contamination of nurses and the environmental contamination of working surface will be performed separately in an other study.

administration of antineoplastic drugs (ADs) is more and more widespread. In France, more than 320000 people were treated with $\mathrm{AD}$ in $2015 .{ }^{1}$ This leads to an increase in the use of these products by health professionals in terms of frequency and quantities handled and therefore to an increase in occupational exposure to these substances. According to the Sumer survey conducted with occupational physicians in 2010, more than 49400 employees were potentially exposed to these drugs in France ${ }^{2}$ and more than 5.5 million employees in the USA in $2003 .{ }^{3}$ Several professions are concerned by this exposure, including pharmacist technicians, pharmacists, couriers, nurses, assistant nurses, hospital agents and doctors. 
More than 100 ADs are currently marketed. ${ }^{4}$ Most are on the list of 'dangerous to handle' medicines issued by the US National Institute for Occupational Research and Safety in $2004^{3}$ because of their carcinogenic, mutagenic and/or reprotoxic effects (CMR). Thirty-eight ADs have been evaluated by IARC: 13 are classified as a human carcinogens (group 1), 11 as probably carcinogen (group 2A), 7 may be carcinogenic (group 2B) and 7 are not classifiable for human carcinogenicity (group 3 ).

Since the 1970s, epidemiological studies conducted with nurses handling $\mathrm{AD}$ have shown an increase in risk of cancers ${ }^{56}$ such as leukemias ${ }^{5}$ and/or reprotoxic effects. The reported reprotoxic effects are: spontaneous abortions, ${ }^{7-13}$ fetal malformations, ${ }^{614-17}$ decreased fertility, ${ }^{13} 1819$ risk of uterine growth retardation and prematurity. ${ }^{19}$

Several international studies conducted between the 1980s and 2003 report that pharmacist assistants and nurses handling these drugs were contaminated, with rates exceeding $75 \%$ or even $90 \%$ of staff in some studies. ${ }^{20-22}$ Moreover, numerous studies show surface contamination of workplace. ${ }^{23}$

Surface sampling is a useful tool in order to identify sources of environmental contamination, to help in the implementation of corrective measures, to verify the effectiveness of the surface decontamination process and to insure a monitoring of these surfaces. Surface sampling is complementary to biomonitoring, which is the best approach to measure internal contamination, that is, $\mathrm{AD}$ detection in urines of exposed healthcare professionals. Indeed, unlike metrology of surface contamination, biomonitoring allows to take into account at the level of each individual, all exposure pathways (respiratory, dermal and oral), the wearing or not of the protective equipment, the effectiveness of the type of protective equipment, gestures and professional practices, personal hygiene and quantities handled. Several analytical methods have been published for surface metrology of $\mathrm{AD}^{24-28}$ and for $\mathrm{AD}$ urine biomonitoring. ${ }^{29-32}$ More than 17 ADs or their urine metabolites can be detected with these methods. The limit of detection (LOD) value in urine, for six of them, is from $0.01^{32-34}$ to $0.02 \mathrm{ng} / \mathrm{L} .^{35}$ For the others, the LOD value in urine is from 0.05 to $1 \mathrm{ng} / \mathrm{L}^{36}$

In the absence of reference biological value for occupational $\mathrm{AD}$ exposure, the long-term effects of occupational low-intensity exposure to these CMR products should lead to a reduction in exposures to the lowest possible level.

During occupational exposure, the contamination can take place by the respiratory and/or cutaneous and/ or oral route. ${ }^{23}$ It can occur directly during the reception, preparation, transport, injection of the drug and the handling of waste or indirectly through the patients and their excreta (vomit, urine, stool, sweat), sheets and soiled linen. ${ }^{23}{ }^{37}$ In order to limit these exposures and to guarantee the safety of employees, centralised reconstitution units for chemotherapies have been created in healthcare establishments and recommendations have been drawn up by government agencies and other occupational health organisations. ${ }^{3} 38$ Despite the recommendations and the improvements made in terms of safety on the handling and transport of these drugs, several recent studies show that the problem of contamination is still relevant, both in the working environment ${ }^{23}{ }^{39-43}$ and for the professionals themselves. 333594 44-51 Currently, scientific reviews report that there is no significant correlation between $\mathrm{AD}$ surface monitoring and $\mathrm{AD}$ urine monitoring. ${ }^{40}$ In this context, there is no disadvantage in conducting both studies separately.

Above reported internal contamination, data show that preventive measures are not currently sufficiently controlled, confirmed by Graeve $e t a .^{52}$ It is, thus, necessary to understand the determinants of exposure.

Very little current data are available on the internal contamination of French healthcare professionals exposed to $\mathrm{AD}$. The protocol detailed in this paper, aims to collect data on $\mathrm{AD}$ internal contamination in nurses and understand factors associated with this contamination.

\section{OBJECTIVES}

The main objective of this protocol is to evaluate the rate of internal contamination by $\mathrm{AD}$ in nurses administering $\mathrm{AD}$ and/or taking care of patients treated with these molecules, in two French hospitals. This rate will be described globally and then stratified by care department.

The secondary objectives are: (1) to describe for each studied $\mathrm{AD}$ the rate of internal contamination among the nurses in the study, and the concentrations associated with this contamination; (2) to identify factors associated with internal contamination in this study (exposure characteristics and use of protective equipments by nurses).

\section{METHODS AND ANALYSIS}

This study is a cross-sectional, descriptive, prospective multicentre study conducted in two French hospitals (University Hospital of Bordeaux and University Cancer Institute of Toulouse (IUCT)-Oncopole).

Eleven hospitals care departments, having an activity in the management of patients with cancer treated with any of the following AD: cyclophosphamide, ifosfamide, methotrexate, 5-fluorouracil and/or doxorubicin, were chosen for this study.

The target population is nurses occupationally exposed to the studied $\mathrm{AD}$.

\section{ELIGIBILITY CRITERIA}

The three following inclusion criteria are required: (1) be a nurse practising in one of the selected care departments where at least one of the five studied AD is handled; (2) handle at least one of the five studied $\mathrm{AD}$ and/or take care of a patient treated with one of the five studied $\mathrm{AD}$ on the day of study participation (ie, day of urine samples 
Table 1 Collected data from the self-questionnaire administered to nurses concerning $A D$ handling the day of inclusion (the day of urine sample collection)

$\begin{array}{ll}\begin{array}{l}\text { Day of AD handling } \\ \text { Work schedule the previous } 7 \\ \text { days }\end{array} & \text { Day of sample urine } \\ & \text { collection } \\ \text { Work shift } & \text { Work } / \text { no work (detailed } \\ & \text { for each } 7 \text { days) }\end{array}$

Exposure/manipulation to any Name of AD handling of the five $A D^{*}$

$\begin{array}{ll}\text { Performed tasks (for each task } & \text { AD infusion bags } \\ \text { the } \mathrm{n}^{\circ} \text { of task and AD nature } & \text { reception } \\ \text { are specified): } & \text { Opening of the package } \\ & \text { of AD infusion bags } \\ & \text { AD infusion } \\ & \text { Use of closed system } \\ & \text { transfer device } \\ & \text { Tubing purge } \\ & \text { Adjustment of the tubing } \\ & \text { flow } \\ & \text { Tubing disconnection } \\ & \text { Unscrewing needle } \\ & \text { Deposit of AD waste in } \\ & \text { bin } \\ & \text { Bin evacuation } \\ \text { Total handled amount (in mg) } & \text { Detailed data for each AD } \\ \text { Route of administration for } & \text { IV } \\ \text { each AD: } & \text { IM } \\ & \text { Oral } \\ & \text { Dermal } \\ & \text { Intrathecal }\end{array}$

Perception of each participant on the department activity

Accidental exposure event ${ }^{*} \dagger$ (ex: needlestick, reversal or leakage of pockets...),
- Event nature and $n^{\circ}$ of events

- AD concerned by this event

- Associated clinical symptoms

- Declared event to occupational physician

*Data will also be collected for the 7 days prior to the day of study participation.

†Data will also be collected for all the career.

$A D$, antineoplastic drugs; IM, Intramuscular; IV, Intravenous.

collection) and (3) agree to participate in the study and sign the participation consent form.

Some work tasks (table 1) expose workers more than others (table 2) in term of level of AD concentration (AD preparation, patient's urine, washing water after the patient had been washed and cleaning water after a patient toilet had been cleaned, ...). ${ }^{37}$ However, the industrial sanitary rules (smoking, washing hands and onychophagia...) and the wearing of personal protective equipment (PPE) according to the tasks are not always respected. As a result, some less exposing tasks may cause higher workers contamination level than more exposing
Table 2 Collected data from the self-questionnaire administered to nurses concerning take care modalities of AD-treated patients the day of inclusion (the day of urine sample collection)

$\mathrm{N}^{\circ}$ of treated $\quad$ Patient treatment on the day of patients who participation.

received an studied - Patient treatment within the 7 days

$A D\left(n^{\circ}\right.$ and $A D$ before the day of participation.

nature) that nurse

has taking care the

day of participation

$\begin{aligned} & \text { Performed tasks: } \text { Direct contact with treated patients } \\ & \text { (help to wash, handling of treated } \\ & \text { patient) } \\ & \text { Handling of treated patient excreta } \\ & \text { (vomit, urine, faeces, expectoration, } \\ & \text { soiled sheets) } \\ & \text { Participation in cleaning } \\ & \text { chemotherapy treatment room } \\ & \text { Cleaning room of treated patient } \\ & \text { Cleaning sanitary facilities of treated } \\ & \text { patient } \\ &- \text { Insertion or removal of an urinary } \\ & \text { catheter } \\ & \text { Change of drape or bed repair of a } \\ & \text { treated patient } \\ & \text { Deposit of treated patient excreta } \\ & \text { in bin } \\ & \text { Bin evacuation. }\end{aligned}$

$A D$, antineoplastic drugs.

tasks. Indeed, Fransman $e t a l,{ }^{37}$ highlight levels of external hand contamination higher for tasks such as washing treated patients, removing bed sheets and handling urine of treated patients compared with drug preparation and toilet cleaning tasks. Therefore, for the second inclusion criteria, all nurses will be included whatever the task done (AD handling and/or take care of AD-treated patient) during the day of the participation to the study participation.

The exclusion criteria are: (1) be a student nurse; (2) be treated with one of the five studied $\mathrm{AD}$ or have been treated with any in the year prior to the day of study participation and (3) have at home a person treated with one of the five studied $\mathrm{AD}$, in the month before the day of study participation.

\section{STUDY DESIGN}

The study will be conducted in six steps.

\section{Step 1: development of analytical methods for quantification} of $A D$ urine biomarkers

Analytical methods will be developed in the Pharmacology and Toxicology Laboratory of the Bordeaux University Hospital in accordance to the European Medecines Agency (EMEA) guideline. ${ }^{53}$ These methods use an ultra-high-performance liquid chromatography 
system coupled with tandem mass spectrometry characterised by high sensitivity and high specificity (5500 QTrap, Sciex). AD urine biomarkers will be the $\mathrm{AD}$ themselves with the exception of 5-fluorouracil, which is not detectable in urine. For this molecule, its urinary metabolite, alfa-fluoro-beta-alanine (FBAL), will be assayed to assess internal contamination. Two methods have been already validated ${ }^{33}$ but the limit of quantification (LOQ) will be improved. Two other methods are developed for this study for the determination of 5-fluorouracil metabolite (FBAL) $)^{35}$ and doxorubicin urine biomarkers. These methods will be robust and highly sensitive with LOQ adapted to this type of study, that is, very low LOQ values allowing detection of urine $\mathrm{AD}$ traces of the order of $\mathrm{ng} / \mathrm{L}$.

For each $\mathrm{AD}$, isotopic internal standard is added in each urine sample to normalise urine matrix effect. Stability of each $\mathrm{AD}$ in urine sample is studied under different conditions of storage $\left(+20^{\circ} \mathrm{C}\right.$ for 24 hours with and without light, at $+4^{\circ} \mathrm{C}$ for 72 hours, at $-20^{\circ} \mathrm{C}$ for 1 month and 1 year, and after three freeze-thaw cycles in urine). A postpreparative stability was conducted by analysing extracted urine samples kept under auto-sampler conditions $\left(+15^{\circ} \mathrm{C}\right)$ for 72 hours.

\section{Step 2: study of the workplace and organisation around $A D$ in each care department}

A hygienist of the occupational medicine department will observe the activities around $\mathrm{AD}$ in each selected care department at the end of the urine sample and self-questionnaire collection. Collective and individual protection equipment available in each department as well as the professional practices observed will be reported in this study of the workplace. A description of the complete organisation around $\mathrm{AD}$ and excreta of treated patients within each care department will also be carried out: $\mathrm{AD}$ reception in the department, administration to patients, disposal of waste. All these observations will be collected and reported in a standardised way for each care department.

\section{Step 3: development of a self-questionnaire}

A self-questionnaire is built, in the light of literature data, concerning work tasks potentially exposing, risk perception. ${ }^{49} 50$ 54-58 In addition, we conducted a pilot study in a healthcare unit that enabled us to carry out a study of the complete organisation around $\mathrm{AD}$ and excreta of treated patients and to collect tasks performed, type and wearing of PPE. During this pilot study, a draft version was pretested on a small group of nurses. When it was necessary, questions were changed according to the feedback of the nurses. A final version was elaborated and will be used in this study.

The aim of this self-questionnaire is to collect several data: sociodemographic and occupational data (table 3), data concerning $\mathrm{AD}$ handling on the day of inclusion (table 1), data concerning take care modalities of

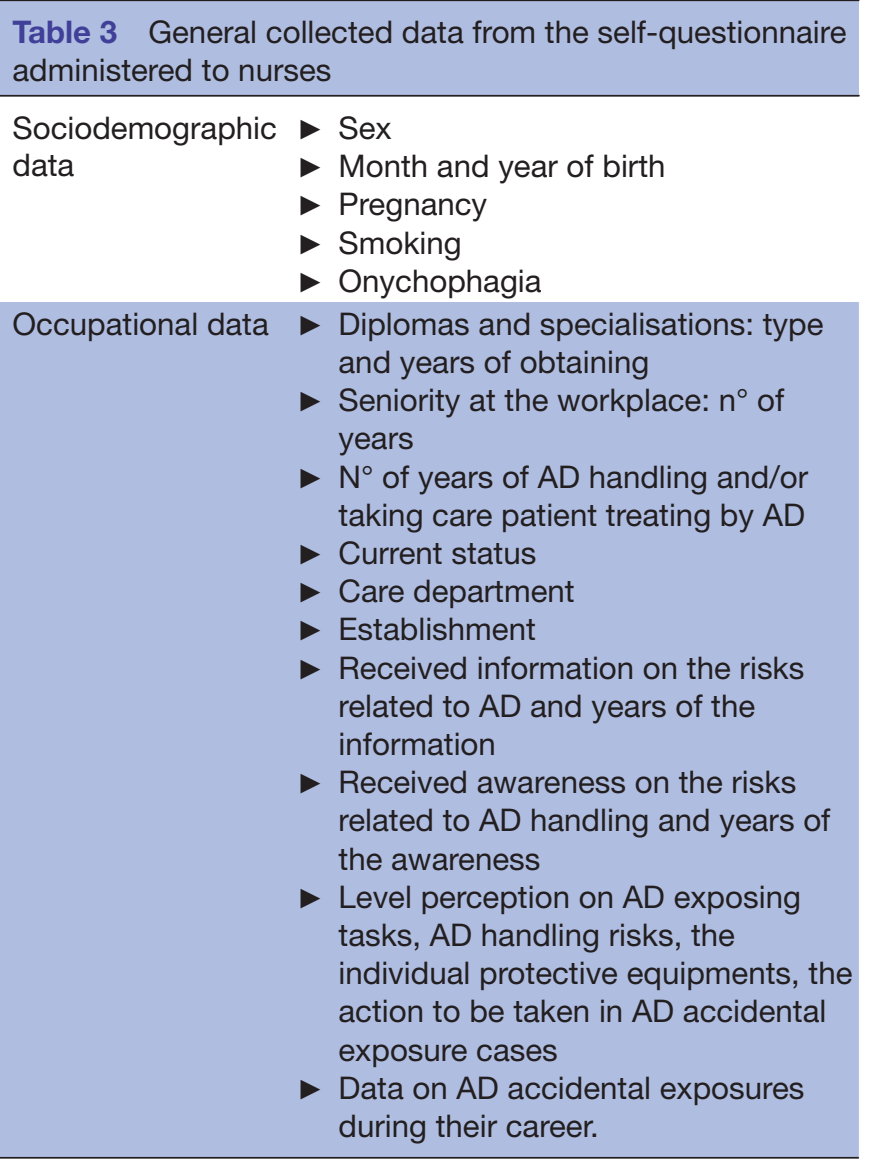

$A D$, antineoplastic drugs.

AD-treated patient (table 2) and PPE worn the day of inclusion (table 4).

For each task listed in tables 1 and 2, the influence of the questionnaire on the nurse practices on the day of participation and for the future is asked. For each task listed in tables 1 and 2, PPEs (table 4) that the nurse wears the day of inclusion are asked. For each task the PPE list is exhaustive so as not to influence the nurse in the choice of PPE according to the task.

\section{Step 4: nurses inclusion}

Each nurse from the selected healthcare departments will receive a briefing note prior to inclusion and will be invited to participate in an information meeting about this study. At the end of the meeting, a kit containing the polypropylene pots to collect urine samples, the selfquestionnaire and the participation consent form will be given to each volunteer. During the meeting, the nurse will be asked to collect their urine samples after several days of work. Therefore, the self-questionnaire plans to collect data on work history the previous 7 days before urine samples collection (type of studied AD handling, accidental exposure event). For each nurse, the study participation lasts 24 hours.

Three urine samples will be collected at different times in less than 24 hours (figure 1): the first one within the 3 hours before the start of the work to document an 
Table 4 Collected data from the self-questionnaire administered in nurses concerning personal protective equipment ${ }^{\star}$ (PPE) wearing the day of inclusion $\dagger$

\begin{tabular}{ll}
\hline Wearing and type of clothing & Hat \\
& Plasticised apron \\
Wearing and type of mask & Short sleeve gown \\
& Surgical mask \\
& FFP2 mask \\
Wearing and type of eye & Protective eyewear \\
protection & Visor \\
Wearing and type of gloves & - Latex/vinyl/nitrile/ \\
& polyvinyl chloride \\
& Simple pair or double \\
& Short or long sleeve \\
Performed procedure of hand & Nothing \\
washing after gloves removal & Hand sanitizer use \\
(gloves used after AD handling) & Wash of hands with \\
& water only \\
& Wash of hands with \\
& water and soap \\
\hline
\end{tabular}

*PPE list proposed to each nurse for each performed task. †For each item the use frequency is ask (never, sometimes, systematically).

¥

AD, antineoplastic drugs; FFP, Filtering Facepiece Particles.

internal contamination following exposure the previous days before the study; the second within 2 hours following the end of the work, to document an internal contamination following exposure during the first hours of the day working day; the third between 7 and 10 hours after the end of the work, to document an internal contamination following exposure at the end of the work. The time of the third sampling was chosen to take into account a delayed absorption by the cutaneous way as indicated by Hirst et al..$^{59}$

A document gathering the date and times of urine samples will be attached to the samples. Urine samples will be sent to the pharmacology and toxicology laboratory of Bordeaux university hospital within 72 hours at $+4^{\circ} \mathrm{C}$. Then samples will be aliquoted and stored at $-20^{\circ} \mathrm{C}$ until analysis. At the same time, nurses will complete a self-questionnaire concerning their professional activity throughout the AD handling day. The self-questionnaire is a paper document with a detachable flap. This part will be sent by mail (return postage paid envelopes) to the coordinating centre, which will monitor the completed data and the other part will be kept by the nurse. After urine sample reception by the laboratory, the latter will immediately informs the coordinating centre of this reception. The coordinating centre will contact the nurses within 7 days if the self-questionnaire has not been received yet, limiting possible loss of data. Moreover, in case of missing or discordant data, each subject will be contacted by a member of the coordinating centre to complete the self-questionnaire.

\section{Step 5: urine assays}

For each urine sample, four extraction methods followed by a validated analytical method will be performed. Moreover, urine creatinine will be analysed for each urine sample to account for dilution. ${ }^{6061}$ The result will be expressed according to the $\mathrm{AD}$ concentration level (ng/L and $\mathrm{ng} / \mathrm{g}$ of urinary creatinine). Participant will be considered as contaminated when at least one of the five studied $\mathrm{AD}$, is detected in at least one of the three collected urine samples.

\section{Step 6: data analysis}

Statistical analysis will be performed using SAS software (SAS Institute, V.9.3) by a statistician from the coordinating centre.

The rate of internal contamination will be calculated by reporting the number of contaminated subjects by at least one of the studied $\mathrm{AD}$ to the total number of subjects included and will be expressed as a percentage. This proportion will be estimated globally then detailed by molecule and department. The extent of the concentration levels achieved will also be described for each sampling time and each drug.

The statistical analysis will include a global descriptive analysis of collected data from the selfadministered questionnaire. Then factors associated with internal contamination of nurses will be studied using a multivariate logistic regression model. An univariate analysis will be used to select the variables, which will be included into the multivariate model at the significance level of $25 \%$. A step-by-step method

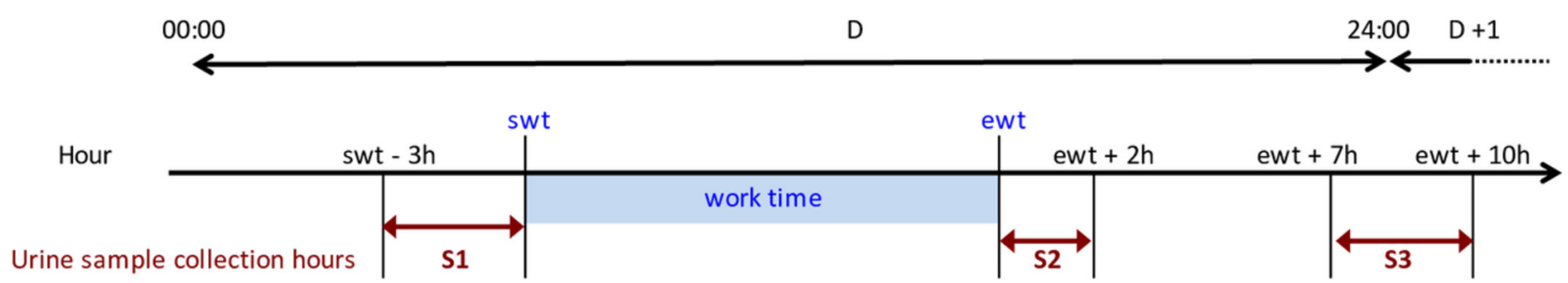

Figure 1 Urine samples collection time. D, day of participation of nurses in the study; swt, start work time; ewt, end work time; S1, urine sample collected within 3 hours before the start of the work; S2, urine sample collected within 2 hours following the end of the work; S3, urine sample collected between 7 and 10 hours following the end of the work. 
will be used to select the significant variables at the $5 \%$ threshold in the final multivariate model. Interactions and confounders will be sought and tested throughout the modelling.

\section{ENDPOINTS}

The primary endpoint will be the absence or presence of internal $\mathrm{AD}$ contamination for each nurse. It will be determined in the light of $\mathrm{AD}$ urine assays results. A subject will be considered contaminated if at least one of the five $\mathrm{AD}$ is detected in at least one of the three urine samples.

Others endpoints will be studied:

- AD internal contamination stratified by drug and by sampling times (S1, S2 and S3).

- Descriptions of the studied population from the selfquestionnaire data: (1) sociodemographic data; (2) occupational data; (3) AD handling data and (4) take care modalities of treated patients by studied AD. This description will be stratified by centre and by department (stratification conditioned by the number of participants).

Following these descriptions, the factors, described above, associated with internal contamination of nurses will be studied.

\section{Calculation of the number of participants}

The main objective is to estimate the rate of nurse internal $\mathrm{AD}$ contamination in two hospitals. Thus, no sample size calculation will be made for the main criterion since it will be estimated from the total eligible population. Given the total number of nurses working in the 11 selected care departments to participate in the study, 300 nurses are potentially eligible.

Since this protocol is not very constraining for participants, with only 1 day of inclusion and only three noninvasive urinary samples, we expect a participation rate around $75 \%$ for the nursing staff. With this participation rate, the number of recruited subjects expected for this study will be about 225 subjects.

\section{Impact of the study}

The impact of this study will be: (1) the assessment of the rate of nurses internal contamination in care departments, (2) awareness of nurses about their contamination, (3) implementation of corrective actions, (4) improvement of $\mathrm{AD}$ handling and transport safety, (5) improvement of nurse professional practices and particularly the use of protection equipment, (6) powerful (highly sensitive) analytical tools set up in the laboratory, adapted to the follow-up of professionals exposed to 'dangerous handling drugs' and available for occupational physicians.

\section{Patient and public involvement}

The research question and the protocol have been developed by a multidisciplinary team and an analysis of the workplace. As indicated in step 3 of the study protocol, a pilot study was previously conducted, in a healthcare unit of Bordeaux university hospital during which a draft version of a self-questionnaire was developed and pretested on a small group of nurses and modify according to their feedback.

Representative workers of hospital personnel, managers of the two hospitals, health managers will be informed of the study. Each nurse from the selected care departments will receive a briefing note prior to inclusion and will be invited to participate in an information meeting about this study.

\section{Ethics and dissemination}

Collected data will be subject to a computerised treatment in the Coordinating Centre of this study (Research Platform in Pharmacoepidemiology, BPE, CIC Bordeaux CIC1401) in compliance with law $\mathrm{n}^{\circ}$ 78-17 (6 January 1978) relating to data processing, files and freedoms modified by the French law 2004801 (6 August 2004). Collected data will be kept during 5 years.

The results from this study will be submitted to peerreviewed journals and reported at suitable national and international conferences or workshops.

\section{Author affiliations}

${ }^{1}$ Inserm U1219, Bordeaux Population Health, Université de Bordeaux, Bordeaux, France

${ }^{2}$ Consultation de Pathologie Professionnelle et de l'environnement, CHU Timone, AP-HM, Marseille, France

${ }^{3}$ Univ. of Bordeaux, Bordeaux, France

${ }^{4}$ Laboratoire de Pharmacologie Clinique et Toxicologie, CHU de Bordeaux, Bordeaux, France

${ }^{5}$ Bordeaux PharmacoEpi (BPE, CIC 1401), Université de Bordeaux, Talence, France ${ }^{6} \mathrm{GH}$ Pellegrin, Pôle de Santé Publique, Service de Médecine du Travail et Pathologies professionnelles, CHU de Bordeaux, Bordeaux, France

Contributors MCR and MM designed the initial study concept. CV-E, AV, IB, SM-P and BM contributed to the design of the study and development of the protocol. MCR, CV-E, EB, AV and MR participate to develop the selfquestionnaire. AV and MCR wrote the manuscript with the contributions of others authors for each work packages. All authors have taken part in the academic discussions of the manuscript's content, and in revising the article. All authors read and approved the final manuscript. We apologized Pr Nicholas Moore for his proofreading.

Funding This work represents independent research. It is supported by a grant from the French Ministry of Health (grant reference number (PHRC-I n 13-077)).

Competing interests None declared.

Patient consent for publication Not required.

Ethics approval The study protocol has been approved by the French Advisory Committee on the Treatment of Information in Health Research (CCTIRS) and by the French Data Protection Authority (CNIL).

Provenance and peer review Not commissioned; externally peer reviewed.

Open access This is an open access article distributed in accordance with the Creative Commons Attribution Non Commercial (CC BY-NC 4.0) license, which permits others to distribute, remix, adapt, build upon this work non-commercially, and license their derivative works on different terms, provided the original work is properly cited, appropriate credit is given, any changes made indicated, and the use is non-commercial. See: http://creativecommons.org/licenses/by-nc/4.0/.

ORCID iD

Mireille Canal-Raffin http://orcid.org/0000-0003-4140-1639 


\section{REFERENCES}

1 Anonymous. [Healthcare]: French National Cancer Institute, 2019. Available: http://lesdonnees.e-cancer.fr/Themes/Soins [Accessed 12 Jul 2019]

2 Amira S. [Occupational risks by profession. 2010 Sumer study]. SynthèseStat' Direction de l'animation de la recherche, des études et des statistiques (DARES) 2014:1-221.

3 Anonymous. NIOSH alert: preventing occupational exposures to antineoplastic and other hazardous drugs in health care settings (publication $n^{\circ} 2004-165$. Centers for Disease Control and Prevention - National Institute for Occupational Safety and Health, 2004: 58.

4 Anonymous. NIOSH list of antineoplastic and other hazardous drugs in healthcare settings (publication No. 2016-161. Department of health and human services. Centers for Disease Control and Prevention. National Institute for Occupational Safety and Health, 2016: 42.

5 Skov T, Maarup B, Olsen J, et al. Leukaemia and reproductive outcome among nurses handling antineoplastic drugs. Occup Environ Med 1992;49:855-61.

6 Ratner PA, Spinelli JJ, Beking K, et al. Cancer incidence and adverse pregnancy outcome in registered nurses potentially exposed to antineoplastic drugs. BMC Nurs 2010;9:15.

7 Selevan SG, Lindbohm M-L, Hornung RW, et al. A study of occupational exposure to antineoplastic drugs and fetal loss in nurses. N Engl J Med 1985;313:1173-8.

8 Rogers B, Emmett EA. Handling antineoplastic agents: urine mutagenicity in nurses. Image 1987;19:108-13.

9 Stucker I, Caillard JF, Collin R, et al. Risk of spontaneous abortion among nurses handling antineoplastic drugs. Scand J Work Environ Health 1990;16:102-7.

10 Valanis B, Vollmer WM, Steele P. Occupational exposure to antineoplastic agents: self-reported miscarriages and stillbirths among nurses and pharmacists. J Occup Environ Med 1999;41:632-8

11 Lawson CC, Rocheleau CM, Whelan EA, et al. Occupational exposures among nurses and risk of spontaneous abortion. Am J Obstet Gynecol 2012;206:327.e1-8.

12 Dranitsaris $\mathrm{G}$, Johnston M, Poirier S, et al. Are health care providers who work with cancer drugs at an increased risk for toxic events? A systematic review and meta-analysis of the literature. J Oncol Pharm Pract 2005;11:69-78.

13 Zhang X, Zheng Q, Lv Y, et al. Evaluation of adverse health risks associated with antineoplastic drug exposure in nurses at two Chinese hospitals: the effects of implementing a pharmacy intravenous admixture service. Am J Ind Med 2016;59:264-73.

14 Hemminki K, Kyyrönen P, Lindbohm ML. Spontaneous abortions and malformations in the offspring of nurses exposed to anaesthetic gases, cytostatic drugs, and other potential hazards in hospitals, based on registered information of outcome. J Epidemiol Community Health 1985;39:141-7.

15 McDonald AD, McDonald JC, Armstrong B, et al. Congenital defects and work in pregnancy. Occup Environ Med 1988;45:581-8.

16 McAbee RR, Gallucci BJ, Checkoway H. Adverse reproductive outcomes and occupational exposures among nurses: an investigation of multiple hazardous exposures. Aaohn $J$ 1993;41:110-9.

17 Lorente C, Cordier S, Bergeret A, et al. Maternal occupational risk factors for oral clefts. occupational exposure and congenital malformation Working group. Scand J Work Environ Health 2000;26:137-45

18 Valanis B, Vollmer W, Labuhn K, et al. Occupational exposure to antineoplastic agents and self-reported infertility among nurses and pharmacists. J Occup Environ Med 1997;39:574-80.

19 Fransman W, Roeleveld N, Peelen S, et al. Nurses with dermal exposure to antineoplastic drugs: reproductive outcomes. Epidemiology 2007;18:112-9.

20 Sessink PJ, Boer KA, Scheefhals AP, et al. Occupational exposure to antineoplastic agents at several departments in a hospital. environmental contamination and excretion of cyclophosphamide and ifosfamide in urine of exposed workers. Int Arch Occup Environ Health 1992;64:105-12.

21 Sessink PJM, Verplanke AJM, Herber RFM, et al. Occupational exposure to antineoplastic agents and parameters for renal dysfunction. Int Arch Occup Environ Health 1997;69:215-8.

22 Ensslin AS, Stoll Y, Pethran A, et al. Biological monitoring of cyclophosphamide and ifosfamide in urine of hospital personnel occupationally exposed to cytostatic drugs. Occup Environ Med 1994:51:229-33.

23 Connor TH, McDiarmid MA. Preventing occupational exposures to antineoplastic drugs in health care settings. CA Cancer J Clin 2006;56:354-65.
24 Guichard N, Rudaz S, Bonnabry P, et al. Validation and uncertainty estimation for trace amounts determination of 25 drugs used in hospital chemotherapy compounding units. J Pharm Biomed Anal 2019;172:139-48.

25 Atgé B, Da Silva Cacao O, Ducint D, et al. Tool development for assessing antineoplastic drugs surface contamination in healthcare services and other workplaces. 39th International Congress of the European Association of Poisons Centres and Clinical Toxicologists (EAPCCT) 21-24 May 2019, Naples, Italy [abstract]. Clinical Toxicology 2019;57:423-602.

26 Colombo M, Jeronimo M, Astrakianakis G, et al. Wipe sampling method and evaluation of environmental variables for assessing surface contamination of 10 antineoplastic drugs by liquid chromatography/tandem mass spectrometry. Ann Work Expo Health 2017:61:1003-14.

27 Dal Bello F, Santoro V, Scarpino V, et al. Antineoplastic drugs determination by HPLC-HRMS(n) to monitor occupational exposure. Drug Test Anal 2016;8:730-7.

28 Nussbaumer S, Geiser L, Sadeghipour F, et al. Wipe sampling procedure coupled to LC-MS/MS analysis for the simultaneous determination of 10 cytotoxic drugs on different surfaces. Anal Bioanal Chem 2012;402:2499-509.

29 Turci R, Sottani C, Spagnoli G, et al. Biological and environmental monitoring of hospital personnel exposed to antineoplastic agents: a review of analytical methods. J Chromatogr B Analyt Technol Biomed Life Sci 2003;789:169-209.

30 Stokvis E, Rosing H, Beijnen JH. Liquid chromatography-mass spectrometry for the quantitative bioanalysis of anticancer drugs. Mass Spectrom Rev 2005;24:887-917.

31 Nussbaumer S, Bonnabry P, Veuthey J-L, et al. Analysis of anticancer drugs: a review. Talanta 2011;85:2265-89.

32 Sottani C, Tranfo G, Bettinelli M, et al. Trace determination of anthracyclines in urine: a new high-performance liquid chromatography/tandem mass spectrometry method for assessing exposure of hospital personnel. Rapid Commun Mass Spectrom 2004:18:2426-36.

33 Canal-Raffin M, Khennoufa K, Martinez B, et al. Highly sensitive LC-MS/MS methods for urinary biological monitoring of occupational exposure to cyclophosphamide, ifosfamide, and methotrexate antineoplastic drugs and routine application. J Chromatogr B Analyt Technol Biomed Life Sci 2016 (published Online First: 2016/12/29).

34 Hedmer M, Tinnerberg H, Axmon A, et al. Environmental and biological monitoring of antineoplastic drugs in four workplaces in a Swedish Hospital. Int Arch Occup Environ Health 2008;81:899-911.

35 Dhersin A, Atgé B, Martinez B, et al. Biomonitoring of occupational exposure to 5 -FU by assaying $\alpha$-fluoro- $\beta$-alanine in urine with a highly sensitive UHPLC-MS/MS method. Analyst 2018;143:4110-7.

36 Mathias PI, Connor TH, B'Hymer C. A review of high performance liquid chromatographic-mass spectrometric urinary methods for anticancer drug exposure of health care workers. J Chromatogr $B$ Analyt Technol Biomed Life Sci 2017;1060:316-24.

37 Fransman W, Vermeulen R, Kromhout H. Dermal exposure to cyclophosphamide in hospitals during preparation, nursing and cleaning activities. Int Arch Occup Environ Health 2005;78:403-12.

38 Mathias PI, MacKenzie BA, Toennis CA, et al. Survey of guidelines and current practices for safe handling of antineoplastic and other hazardous drugs used in 24 countries. J Oncol Pharm Pract 2019;25:148-62

39 Barbieri A, Nucci MC, Sabatini L, et al. Occupational exposure to antineoplastic drugs in a hospital setting: biological and environmental monitoring]. Epidemiol Prev 2005;29:87-90.

40 Kibby T. A review of surface wipe sampling compared to biologic monitoring for occupational exposure to antineoplastic drugs. J Occup Environ Hyg 2017;14:159-74.

41 Chauchat L, Tanguay C, Caron NJ, et al. Surface contamination with ten antineoplastic drugs in 83 Canadian centers. J Oncol Pharm Pract 2019;25:1089-98.

42 Koller M, Böhlandt A, Haberl C, et al. Environmental and biological monitoring on an oncology ward during a complete working week. Toxicol Lett 2018;298:158-63.

43 Dugheri S, Bonari A, Pompilio I, et al. A new approach to assessing occupational exposure to antineoplastic drugs in hospital environments. Arh Hig Rada Toksikol 2018;69:226-37.

44 Sugiura S, Nakanishi H, Asano M, et al. Multicenter study for environmental and biological monitoring of occupational exposure to cyclophosphamide in Japan. J Oncol Pharm Pract 2011;17:20-8.

45 Sabatini L, Barbieri A, Lodi V, et al. Biological monitoring of occupational exposure to antineoplastic drugs in hospital settings. Med Lav 2012;103:394-401

46 Poupeau C, Roland C, Bussieres JF. Surveillance urinaire des professionnels de la santé exposés aux antinéoplasiques dans le 
cadre de leur travail : revue de la littérature de 2010 à 2015. Can J Hosp Pharm 2016;69:376-87.

47 Hon C-Y, Teschke K, Shen H, et al. Antineoplastic drug contamination in the urine of Canadian healthcare workers. Int Arch Occup Environ Health 2015;88:933-41.

48 Friese CR, McArdle C, Zhao T, et al. Antineoplastic drug exposure in an ambulatory setting. Cancer Nurs 2015;38:111-7.

49 Ramphal R, Bains T, Goulet G, et al. Occupational exposure to chemotherapy of pharmacy personnel at a single centre. Can J Hosp Pharm 2015;68:104-12.

50 Ramphal R, Bains T, Vaillancourt R, et al. Occupational exposure to cyclophosphamide in nurses at a single center. J Occup Environ Med 2014;56:304-12.

51 Baniasadi S, Alehashem M, Yunesian M, et al. Biological monitoring of healthcare workers exposed to antineoplastic drugs: urinary assessment of cyclophosphamide and ifosfamide. Iran J Pharm Res 2018;17:1458-64.

52 Graeve CU, McGovern PM, Alexander B, et al. Occupational exposure to antineoplastic agents. Workplace Health Saf 2017;65:9-20.

53 Anonymous. Guideline on bioanalytical method validation. European Medicines Agency, 2011: 23.

54 Hon C-Y, Teschke K, Shen H. Health Care Workers' Knowledge, Perceptions, and Behaviors Regarding Antineoplastic Drugs:
Survey From British Columbia, Canada. J Occup Environ Hyg 2015;12:669-77.

55 Steege AL, Boiano JM, Sweeney MH. NIOSH health and safety practices survey of healthcare workers: training and awareness of employer safety procedures. Am J Ind Med 2014;57:640-52.

56 Polovich M, Clark PC. Factors influencing oncology nurses' use of hazardous drug safe-handling precautions. Oncol Nurs Forum 2012;39:E299-309.

57 Connor TH, DeBord DG, Pretty JR, et al. Evaluation of antineoplastic drug exposure of health care workers at three university-based us cancer centers. J Occup Environ Med 2010;52:1019-27.

58 McDiarmid MA, Oliver MS, Roth TS, et al. Chromosome 5 and 7 abnormalities in oncology personnel handling anticancer drugs. $J$ Occup Environ Med 2010;52:1028-34.

59 Hirst M, Mills D, Tse S, et al. Occupational exposure to cyclophosphamide. The Lancet 1984;323:186-8.

60 Newman MA, Valanis BG, Schoeny RS, et al. Urinary biological monitoring markers of anticancer drug exposure in oncology nurses. Am J Public Health 1994;84:852-5.

61 Anonymous. Biological monitoring of chemical exposure in the workplace guidelines. World Health Organization, 1996: 314. 